\title{
Ramadan fasting and newborn's birth weight in pregnant Muslim women in The Netherlands
}

\author{
Ary I. Savitri ${ }^{1}$, Nasim Yadegari ${ }^{2}$, Julia Bakker ${ }^{2}$, Reyn J. G. van Ewijk ${ }^{3}$, Diederick E. Grobbee ${ }^{1}$, \\ Rebecca C. Painter ${ }^{2}$, Cuno S. P. M. Uiterwaal ${ }^{1}$ and Tessa J. Roseboom ${ }^{2,4_{*}}$ \\ ${ }^{1}$ Julius Center for Health Sciences and Primary Care, University Medical Center Utrecht, Utrecht, The Netherlands \\ ${ }^{2}$ Department of Obstetrics and Gynecology, Academic Medical Center, Meibergdreef 9, 1105 AZ Amsterdam, The Netherlands \\ ${ }^{3}$ Institute of Medical Biostatistics, Epidemiology, and Informatics, University Medical Center, Mainz, Germany \\ ${ }^{4}$ Department of Clinical Epidemiology, Biostatistics and Bioinformatics, Academic Medical Center, Meibergdreef 9 , \\ 1105 AZ Amsterdam, The Netherlands \\ (Submitted 30 January 2014 - Final revision received 2 June 2014 - Accepted 9 July 2014 - First published online 18 September 2014)
}

\begin{abstract}
Many Muslim women worldwide are pregnant during Ramadan and adhere to Ramadan fasting during pregnancy. In the present study, we determined whether maternal adherence to Ramadan fasting during pregnancy has an impact on the birth weight of the newborn, and whether the effects differed according to trimester in which Ramadan fasting took place. A prospective cohort study was conducted in 130 pregnant Muslim women who attended antenatal care in Amsterdam and Zaanstad, The Netherlands. Data on adherence to Ramadan fasting during pregnancy and demographics were self-reported by pregnant women, and the outcome of the newborn was retrieved from medical records after delivery. The results showed that half of all the women adhered to Ramadan fasting. With strict adherence to Ramadan fasting in pregnancy, the birth weight of newborns tended to be lower than that of newborns of non-fasting mothers, although this was not statistically significant $(-198 \mathrm{~g}, 95 \% \mathrm{CI}-447,51, P=0 \cdot 12)$. Children of mothers who fasted in the first trimester of pregnancy were lighter at birth than those whose mothers had not fasted $(-272 \mathrm{~g}, 95 \% \mathrm{CI}-547,3, P=0 \cdot 05)$. There were no differences in birth weight between children whose mothers had or had not fasted if Ramadan fasting had taken place later in pregnancy. Ramadan fasting during early pregnancy may lead to lower birth weight of newborns. These findings call for further confirmation in larger studies that should also investigate potential implications for perinatal and long-term morbidity and mortality.
\end{abstract}

Key words: Ramadan fasting: Pregnancy: Birth weight

Maternal nutrition and lifestyle during pregnancy have important effects on the health and well-being of the offspring ${ }^{(1)}$. Poor maternal nutrition and stress during pregnancy are associated with decreased birth weight among newborns ${ }^{(2-4)}$. Low birth weight may have substantial effects on the morbidity and mortality of the newborn, both in the short and long terms. Studies have shown consistent relationships between low birth weight and an increased risk of chronic diseases later in life, such as hypertension, CHD, obesity and diabetes mellitus ${ }^{(5-7)}$. Moreover, the effects on the offspring caused by altered maternal nutrition during pregnancy have been demonstrated to vary according to its timing during pregnancy ${ }^{(5)}$.

Lifestyle changes as characterised by intermittent fasting and altered eating and sleeping patterns may take place among pregnant Muslim women if Ramadan coincides with their pregnancy. Ramadan is an annual period of daytime fasting that lasts for a month. During Ramadan, Muslims refrain from food and fluid from dawn to sunset. Smoking and sexual activities are prohibited when fasting. Physical activities during the days are usually reduced, while activities during evenings and nights are increased. All healthy adult Muslims are obliged to fast. Pregnant women and breast-feeding mothers are exempted from this religious obligation if they are worried about their own health or that of their baby. However, many women still fast in order to share spiritual and social experiences with their family ${ }^{(8)}$. Estimates of the proportion of pregnant Muslim women who fast for at least a day during Ramadan range from $50-70 \%$ (Iran) $)^{(9-11)}$ to $70-90 \%$ (England, Singapore, USA, Gambia and Yemen) ${ }^{(12-14)}$, but are unknown among many migrant communities in continental Europe.

Throughout Ramadan, modest undernutrition occurs during the days and continues with a relatively well-nourished state during the nights. Women have been reported to have lower body weight and BMI (weight/height ${ }^{2}$ ) during this period $^{(12,15,16)}$. The degree of lifestyle changes during Ramadan could be different across countries. In many Muslim-predominant

*Corresponding author: T. J. Roseboom, email t.j.roseboom@amc.uva.nl 
countries, the government often reduces the number of working hours during Ramadan and grants several days of public holiday. Some seasonal meals that comprise of foods high in fat, sugar and salt are often served at the end of fasting. Fasting duration also varies for Muslims living in the Northern and Southern hemispheres, as longer summer days mean a longer fasting.

In spite of the widespread adherence to Ramadan fasting, it is still unclear whether this mode of fasting during pregnancy is related to health outcomes of the offspring. A number of studies have reported that maternal fasting during Ramadan has no significant effect on neonatal birth weight and fetal development ${ }^{(9,10,17,18)}$. However, most of these prospective studies were small and did not take into account potential confounders. In two large studies conducted in Birmingham $^{(19)}$ and Unizah (Saudi Arabia) ${ }^{(20)}$, no effect of Ramadan exposure on birth weight has been reported. Yet, effect estimates found in both studies may be subjected to bias since there seems to have been incomplete adjustment for confounders. Inaccuracy of exposure classification may also be an issue in the Birmingham study where distinction of Muslim and non-Muslim Asians were only based on the first three letters of the surname in the birth dataset. A large cohort study among 50000 mothers of Arab descent in the USA has demonstrated a significantly lower birth weight among Muslims who had been in utero during Ramadan. The small difference in birth weight found in that study is probably an underestimate since it also included non-Muslim women and lacked information on the degree to which women had actually fasted ${ }^{(21)}$. Furthermore, a long-term effect of Ramadan was found from a large population study in Indonesia, in which exposure to Ramadan during pregnancy led to smaller and thinner adult body size, poorer general health and increased prevalence of symptoms indicative of coronary heart problems and type 2 diabetes $^{(8,13)}$.

Ramadan is clearly demarcated from the rest of the months, and allows us to study the impact of a short episode of metabolic disturbance during pregnancy on neonatal outcome. In the present study, we investigated the relationship between maternal adherence to Ramadan fasting, the trimester of pregnancy and the birth weight of newborns in a Muslim population living in a Western country.

\section{Methods}

\section{Study design and population}

A cohort study was conducted in the regions of Amsterdam and Zaanstad, The Netherlands, during Ramadan 2010. The study population comprised Muslim women who were pregnant during the month of Ramadan in 2010 (11 August 2010 until 10 September 2010), and who signed informed consent. Women with gestational age less than 4 weeks at the beginning of Ramadan and women who gave birth before the end of Ramadan were excluded from the study. In 2010, Ramadan took place during summer with approximately 13-15 fasting hours each day. At the start of prenatal care, women were classified into two categories based on their risk of developing complications during pregnancy. All midwifery practices, providing care for low-risk pregnancies ( $n$ 34), and hospitals, providing care for high-risk pregnancies ( $n$ 7), in Amsterdam and Zaanstad were asked to participate. Overall, eighteen midwifery practices, three community hospitals, and one university hospital participated. The study was approved by the Medical Ethics Committee of the Academic Medical Center Amsterdam.

Maternal education was used to estimate socio-economic status of the mother. Women were classified into high educational level attained (finished higher vocational, college or tertiary education), low educational level attained (finished primary school, lower vocational or secondary school) or unknown. Maternal smoking during pregnancy and during Ramadan was classified into three categories: non-smoking; infrequent smoking; daily smoking. Ethnicity was classified into three groups: Turkish; Moroccan; other ethnicity.

\section{Data collection}

Data on Ramadan fasting exposure during pregnancy were collected from 13 September 2010 until 31 December 2010 by midwifery students who interviewed the women using questionnaires. In addition, demographic data were collected.

Women were asked to provide written informed consent for retrieval of their medical records after delivery. They were also asked whether they would agree to be approached in the future for long-term follow-up. There were 232 eligible women who had been approached to join the study; 133 of them provided their informed consent and birth-weight data of 130 newborns were accessible from medical records. The flow chart of data collection is shown in Fig. 1. Medical records of women were requested from the relevant obstetrician/gynaecologist to collect birth outcome.

\section{Data analysis}

A multivariable linear regression analysis was performed to determine the relationship between maternal adherence to Ramadan fasting during pregnancy (as the independent variable) and the birth weight of the newborn (as the dependent variable). Maternal adherence to Ramadan fasting was classified into indicator categories: 'fasted half a month or less' or 'fasted more than half a month', with 'did not fast' (if women did not fast at any time) as the reference. To determine whether timing of fasting during pregnancy was important, we compared the trimesters in which Ramadan fasting occurred during pregnancy. Women who fasted (both fasted half a month or less and fasted more than half a month) were classified into the categories: fasted in the first trimester; fasted in the second trimester; fasted in the third trimester. To evaluate whether the association between maternal adherence to Ramadan fasting and birth weight of newborns depended on the trimester of pregnancy in which Ramadan occurred, we used the likelihood ratio test to compare models without and with interaction terms for adherence to fasting and trimester of pregnancy.

Maternal smoking, ethnicity, first pregnancy, risk (e.g. care) classification of pregnancy and maternal education were a priori considered as possible confounders. 


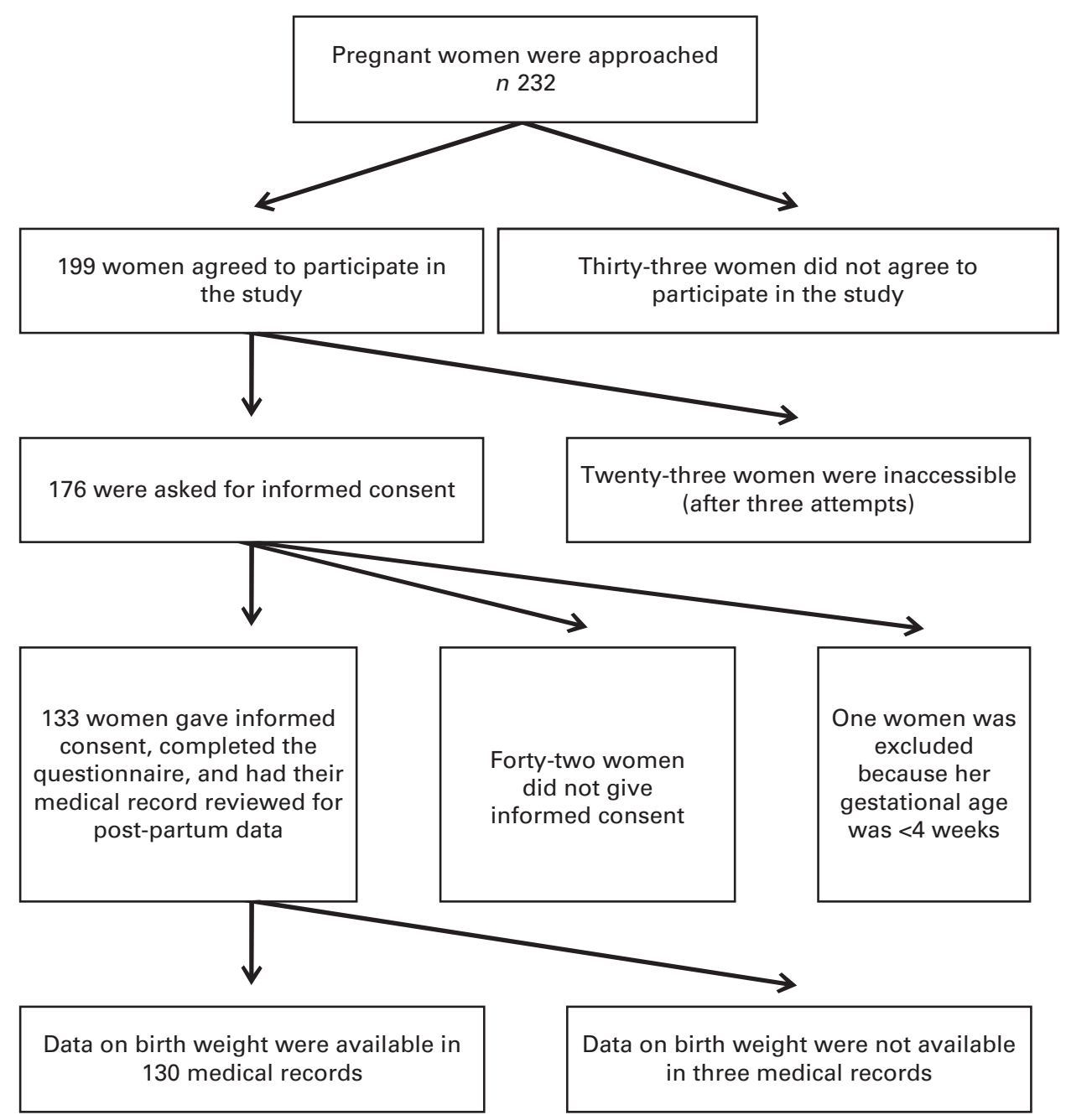

Fig. 1. Flow chart of data collection.

Results are expressed as linear regression coefficients with 95\% CI and corresponding $P$ values. Statistical significance was considered at a two-sided $P$ value $<0 \cdot 05$. Analyses were performed using SPSS version 20.0 for Windows (IBM Corporation) and R open-source software (The R Foundation for Statistical Computing) using the $1 \mathrm{~m}$ function.

\section{Results}

\section{General characteristics}

The general characteristics of women with regard to their adherence to fasting are shown in Table 1. Of all the participants, seventy $(53.8 \%)$ fasted to some extent, of whom twenty-one (16.2\%) fasted half a month or less and forty-nine (37.7\%) fasted more than half a month during Ramadan. The three adherence to fasting groups were similar in terms of age and having been born outside The Netherlands. Women who fasted half a month or less and women who fasted more than half a month were of similar parity, educational level attained, mean gestational age at the start of Ramadan, and pregnancy risk status when compared with non-fasting women. Smoking was more common in women who did not fast and fasted half a month or less compared with those who fasted more than half a month. Moroccan women fasted more often than Turkish women. No difference was found with respect to gestational duration and sex of the babies.

\section{Adherence to fasting and birth weight of newborns}

Table 2 shows the associations between adherence to Ramadan fasting and the birth weight of newborns, both crude and adjusted. There were associations between Ramadan fasting and birth weight, although none were statistically significant. The newborns of mothers who fasted half a month or less and fasted more than half a month tended to be $163 \cdot 1 \mathrm{~g}$ heavier and $64.6 \mathrm{~g}$ lighter than those of mothers who did not fast. These associations, respectively, changed to 143.7 and $-132.4 \mathrm{~g}$ after adjustment for smoking and ethnicity, to $112 \cdot 1$ and $-169 \cdot 6 \mathrm{~g}$ after further adjustment for nulliparity, and to 95.1 and $-198.1 \mathrm{~g}$ after further adjustment for pregnancy risk classification and socio-economic factors. 
Table 1. Baseline characteristics of women by adherence to fasting (Number of participants and percentages; mean values and standard deviations)

\begin{tabular}{|c|c|c|c|c|c|c|c|}
\hline & \multicolumn{6}{|c|}{ Adherence to Ramadan fasting } & \multirow[b]{3}{*}{$P$} \\
\hline & \multicolumn{2}{|c|}{ Did not fast } & \multicolumn{2}{|c|}{$\begin{array}{l}\text { Fasted half a } \\
\text { month or less }\end{array}$} & \multicolumn{2}{|c|}{$\begin{array}{l}\text { Fasted more than } \\
\text { half a month }\end{array}$} & \\
\hline & Mean & SD & Mean & SD & Mean & SD & \\
\hline$n$ & \multicolumn{2}{|c|}{60} & \multicolumn{2}{|c|}{21} & \multicolumn{2}{|c|}{49} & \\
\hline$\%$ & \multicolumn{2}{|c|}{$46 \cdot 2$} & \multicolumn{2}{|c|}{$16 \cdot 2$} & \multicolumn{2}{|c|}{$37 \cdot 7$} & \\
\hline Maternal age & $29 \cdot 3$ & $4 \cdot 2$ & 28.9 & 4.9 & $28 \cdot 9$ & 4.7 & $0.93^{*}$ \\
\hline Nulliparity (\%) & \multirow{2}{*}{\multicolumn{2}{|c|}{$31 \cdot 7$}} & \multirow{2}{*}{\multicolumn{2}{|c|}{$23 \cdot 8$}} & \multirow{2}{*}{\multicolumn{2}{|c|}{$24 \cdot 5$}} & $0.69 \dagger$ \\
\hline Ethnicity (\%) & & & & & & & $<0.0001 \ddagger$ \\
\hline Turkish & \multicolumn{2}{|c|}{$58 \cdot 3$} & \multicolumn{2}{|c|}{$33 \cdot 3$} & \multicolumn{2}{|c|}{$8 \cdot 2$} & \\
\hline Moroccan & \multicolumn{2}{|c|}{$25 \cdot 0$} & \multicolumn{2}{|c|}{$52 \cdot 4$} & \multicolumn{2}{|c|}{$87 \cdot 8$} & \\
\hline Others & \multirow{2}{*}{\multicolumn{2}{|c|}{$\begin{array}{l}16 \cdot 7 \\
36 \cdot 7\end{array}$}} & \multicolumn{2}{|c|}{$14 \cdot 3$} & \multicolumn{2}{|c|}{$4 \cdot 1$} & \\
\hline Born outside The Netherlands (\%) & & & \multicolumn{2}{|c|}{$38 \cdot 1$} & \multicolumn{2}{|c|}{$38 \cdot 8$} & $0.97 \dagger$ \\
\hline Socio-economic status (\%) & & & & & & $0.61 \ddagger$ \\
\hline High educational level attained & \multicolumn{2}{|c|}{$33 \cdot 3$} & \multicolumn{2}{|c|}{$28 \cdot 6$} & \multicolumn{2}{|c|}{24.5} & \\
\hline Low educational level attained & 65 & & 7 & & & & \\
\hline Unknown & 1 & & & & & & \\
\hline Smoking in Ramadan (\%) & & & & & & & $0.01 \neq$ \\
\hline No & 85 & & 85 & & & & \\
\hline Infrequent & 1 & & & & & & \\
\hline Every day & 13 & & & & & & \\
\hline Smoking outside Ramadan/pregnancy (\%) & 21 & & $1<$ & & & & $0.005 \ddagger$ \\
\hline Gestational age at Ramadan (in weeks) & $18 \cdot 8$ & $8 \cdot 6$ & 17.9 & $10 \cdot 1$ & $16 \cdot 6$ & $8 \cdot 8$ & $0.44^{*}$ \\
\hline Trimester at Ramadan (\%) & & & & & & & $0.36 \ddagger$ \\
\hline I & 30 & & $3 \varepsilon$ & & & & \\
\hline II & 48 & & $2 \varepsilon$ & & & & \\
\hline III & 21 & & 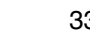 & & & & \\
\hline Pregnancy risk classification (\%) & & & & & & & $0.95 \ddagger$ \\
\hline First line & 93 & & & & & & \\
\hline Second line & 5 & & & & & & \\
\hline Third line & 1 & & & & & & \\
\hline Gestational duration (d) & $277 \cdot 4$ & $8 \cdot 8$ & $277 \cdot 4$ & $9 \cdot 8$ & 278.5 & $17 \cdot 4$ & $0.90^{*}$ \\
\hline Sex of the baby ( $\%$ of female) & 46 & & 45 & & & & $1.00 \dagger$ \\
\hline
\end{tabular}

Timing of fasting during pregnancy and

\section{birth weight of newborns}

A comparison between the trimesters in which Ramadan occurred during pregnancy with respect to the birth weight of newborns is shown in Table 3. The newborns of women who fasted in their first trimester were on average $171 \mathrm{~g}$ lighter (95\% CI $-415,74 \cdot 5, P=0 \cdot 17$ ) than those of non-fasting mothers (reference group). Adjustment for maternal smoking status and ethnicity, parity, pregnancy risk classification and socio-economic factors resulted in a lower birth weight of $272 \mathrm{~g}$ in newborns of women who fasted in their first trimester ( $95 \% \mathrm{CI}-547,3, P=0.05$ ). There were no associations found with respect to birth weight among newborns of women who fasted in the second and third trimesters of their pregnancies.

Table 4 shows the mean birth weights of newborns of women with respect to their adherence to fasting and trimester of pregnancy at the start of Ramadan. The newborns of women who fasted more than half a month in the first trimester had the lowest birth weight, although we could not demonstrate a statistical interaction suggesting the opposing effects of adherence to Ramadan fasting per trimester of exposure $(P=0 \cdot 43)$.

\section{Discussion}

In the present study, we provide direct evidence that maternal Ramadan fasting during early pregnancy in an urban Dutch Muslim population may be associated with some reduction in the birth weight of newborns, although it is of borderline statistical significance. This effect may be particularly marked among women who fasted more than half a month in the first trimester of pregnancy, and was robust after correction for potential confounders.

Our findings are in line with those of an earlier large study, which demonstrated a small reduction in birth weight among babies who were exposed to Ramadan during pregnancy, although that study lacked information on maternal fasting ${ }^{(12)}$. Our findings are also consistent with previous studies, which showed lower birth weight among newborns of women who fasted, particularly if it lasted more than $20 \mathrm{~d}^{(9,22)}$. The present findings are at odds with small studies carried out in predominantly Muslim countries, which found similar birth weight among the babies of women who had fasted during Ramadan and of those who had not ${ }^{(10,11,23)}$. Although these studies did directly assess maternal fasting, confounders (such as other 
Table 2. Relationship between maternal adherence to Ramadan fasting in pregnancy and birth weight of newborns

(Linear regression coefficients and $95 \%$ confidence intervals)

\begin{tabular}{|c|c|c|c|}
\hline & \multicolumn{3}{|c|}{ Birth weight (g) } \\
\hline & $\begin{array}{l}\text { Linear regression } \\
\text { coefficient }^{\star}\end{array}$ & $95 \% \mathrm{Cl}$ & $P$ \\
\hline \multicolumn{4}{|l|}{ Model $1 \dagger$} \\
\hline Did not fast & Reference & & \\
\hline $\begin{array}{l}\text { Fasted half a month } \\
\text { or less }\end{array}$ & $163 \cdot 1$ & $-109 \cdot 7,435 \cdot 9$ & 0.24 \\
\hline $\begin{array}{l}\text { Fasted more than } \\
\text { half a month }\end{array}$ & $-64 \cdot 6$ & $-271 \cdot 7,142 \cdot 6$ & 0.54 \\
\hline \multicolumn{4}{|l|}{ Model 2‡ } \\
\hline Did not fast & Reference & & \\
\hline $\begin{array}{l}\text { Fasted half a month } \\
\text { or less }\end{array}$ & $143 \cdot 7$ & $-133 \cdot 9,421 \cdot 3$ & 0.31 \\
\hline $\begin{array}{l}\text { Fasted more than } \\
\text { half a month }\end{array}$ & $-132 \cdot 4$ & $-381 \cdot 8,117 \cdot 0$ & 0.29 \\
\hline \multicolumn{4}{|l|}{ Model $3 \S$} \\
\hline Did not fast & Reference & & \\
\hline $\begin{array}{l}\text { Fasted half a month } \\
\text { or less }\end{array}$ & $112 \cdot 1$ & $-160 \cdot 6,384 \cdot 7$ & 0.42 \\
\hline $\begin{array}{l}\text { Fasted more than } \\
\text { half a month }\end{array}$ & $-169 \cdot 6$ & $-415 \cdot 2,76 \cdot 1$ & 0.17 \\
\hline \multicolumn{4}{|l|}{ Model 4\| } \\
\hline Did not fast & Reference & & \\
\hline $\begin{array}{l}\text { Fasted half a month } \\
\text { or less }\end{array}$ & $95 \cdot 1$ & $-182 \cdot 0,372 \cdot 2$ & 0.49 \\
\hline $\begin{array}{l}\text { Fasted more than } \\
\text { half a month }\end{array}$ & $-198 \cdot 1$ & $-447 \cdot 4,51 \cdot 2$ & 0.12 \\
\hline
\end{tabular}

* Linear regression coefficients indicated the difference in birth weight $(\mathrm{g})$ with the reference category.

†Crude model.

¥Adjusted for maternal smoking status during Ramadan and pregnancy and maternal ethnicity.

$\S$ Adjusted as for model 2 and for nulliparity.

II Adjusted as for model 3 and for pregnancy risk classification at the start of prenatal care and for socio-economic factors (maternal education).

health-related lifestyles, parity and socio-economic status) were not addressed adequately in their analyses, as confounding is a major issue in this type of research question. Studies that took ultrasound-based fetal growth indices as the outcome also did not show significant differences between offspring of fasting and non-fasting women ${ }^{(24-26)}$. Another explanation for the discrepancy with our findings may be the fact that the number of hours of fasting during Ramadan in our study population was up to $25 \%$ shorter due to the geographical latitude.

The effect of fasting during pregnancy on the birth weight of newborns may be mediated through several mechanisms. Fasting can produce 'accelerated starvation'(27) during pregnancy, with more rapid and marked metabolic and endocrine changes (lower blood glucose level, higher cortisol level and lower lipid level) than in non-pregnant women ${ }^{(25,28,29)}$. Hyperemesis gravidarum may also be more prevalent or severe among fasting women, contributing further to metabolic alterations. A study in Israel has shown a significant increase in the hospital admission of pregnant Muslim women in their first trimester during Ramadan due to hyperemesis gravidarum ${ }^{(30)}$.

The relatively small sample size was a limitation of the present study. A relatively low response rate of 56\% may have induced selection bias, although we found it difficult to perceive how the association could be different among participants and non-participants. We were aware that maternal nutritional status could confound our findings, since it may relate to both birth weight of newborns and maternal adherence to fasting. A significantly higher BMI was reported in mothers who fasted than in mothers who did not fast ${ }^{(10)}$, while other studies have shown no differences in BMI ${ }^{(22,29)}$. We could not correct for BMI due to the absence of data regarding maternal anthropometric status. Data on placental measurements were not accessible in the present study, which prohibits further explanatory analysis. However, we believe that placental measurement was not a confounder in the association between Ramadan fasting and birth weight of newborns. In the present study, we assumed that the fasting and non-fasting women experienced an equivalent level of lifestyle changes, which may include changes in sleeping pattern and duration, nutritional intake and physical activities. Nonetheless, we cannot exclude the possibility that lifestyle changes are dependent of women's fasting adherence and may then have consequences on pregnancy outcome.

To the best of our knowledge, this is the first study to determine Ramadan fasting during pregnancy in Muslim women who mostly originated from the Mediterranean and Eurasian regions, while living in a Western country. These women could have experienced different degrees of lifestyle changes during Ramadan when compared with those living in other countries,

Table 3. Relationship between Ramadan fasting in pregnancy and birth weight of newborns

(Linear regression coefficients and $95 \%$ confidence intervals)

\begin{tabular}{|c|c|c|c|}
\hline & \multicolumn{3}{|c|}{ Birth weight $(\mathrm{g})$} \\
\hline & $\begin{array}{l}\text { Linear regression } \\
\text { coefficient }^{*}\end{array}$ & $95 \% \mathrm{Cl}$ & $P$ \\
\hline \multicolumn{4}{|l|}{ Model $1 \dagger$} \\
\hline Did not fast $(n 60)$ & Reference & & \\
\hline Fasted in T1 ( $n 28)$ & -170.5 & $-415 \cdot 4,74.5$ & 0.17 \\
\hline Fasted in T2 ( $n$ 27) & 141.3 & $-106 \cdot 8,389 \cdot 3$ & 0.26 \\
\hline Fasted in T3 $(n 15)$ & 81.4 & $-227 \cdot 6,390 \cdot 4$ & 0.60 \\
\hline \multicolumn{4}{|l|}{ Model $2 \ddagger$} \\
\hline Did not fast & Reference & & \\
\hline Fasted in T1 & $-208 \cdot 7$ & $-483.9,66.6$ & 0.14 \\
\hline Fasted in T2 & $97 \cdot 3$ & $-165 \cdot 3,359 \cdot 9$ & 0.47 \\
\hline Fasted in T3 & $69 \cdot 0$ & $-266 \cdot 1,404 \cdot 1$ & 0.68 \\
\hline \multicolumn{4}{|l|}{ Model $3 \S$} \\
\hline Did not fast & Reference & & \\
\hline Fasted in T1 & -242.6 & $-513 \cdot 2,28 \cdot 0$ & 0.07 \\
\hline Fasted in T2 & 52.0 & $-207 \cdot 3,311 \cdot 3$ & 0.69 \\
\hline Fasted in T3 & $58 \cdot 8$ & $-269 \cdot 0,386 \cdot 7$ & 0.72 \\
\hline \multicolumn{4}{|l|}{ Model 4\| } \\
\hline Did not fast & Reference & & \\
\hline Fasted in T1 & $-272 \cdot 1$ & $-546 \cdot 9,2 \cdot 8$ & 0.05 \\
\hline Fasted in T2 & $28 \cdot 3$ & $-234.9,291 \cdot 6$ & 0.83 \\
\hline Fasted in T3 & $46 \cdot 8$ & $-289 \cdot 3,382.9$ & 0.78 \\
\hline
\end{tabular}

T1, first trimester; T2, second trimester; T3, third trimester.

* Linear regression coefficients indicated the difference in birth weight $(\mathrm{g})$ with the reference category.

† Crude model.

$\ddagger$ Adjusted for maternal smoking status during Ramadan and pregnancy and maternal ethnicity.

$\S$ Adjusted as for model 2 and for nulliparity.

$\|$ Adjusted as for model 3 and for pregnancy risk classification at the start of prenatal care and for socio-economic factors (maternal education). 
Table 4. Mean birth weights of newborns by adherence to Ramadan fasting and trimester of pregnancy*

\begin{tabular}{lccc}
\hline & \multicolumn{3}{c}{ Mean birth weight (g) } \\
\cline { 2 - 4 } & Did not fast & $\begin{array}{c}\text { Fasted half } \\
\text { a month or less }\end{array}$ & $\begin{array}{c}\text { Fasted more than } \\
\text { half a month }\end{array}$ \\
\hline Trimester 1 & 3421 & 3439 & 3226 \\
Trimester 2 & 3494 & 3862 & 3524 \\
Trimester 3 & 3428 & 3621 & 3467 \\
\hline
\end{tabular}

* $P$ for interaction $=0.43$

thus the present results may be specific to the present study population. Ramadan fasting in pregnancy was reported by $54 \%$ of the women in the present study. This suggests a relatively moderate attitude towards adherence to Ramadan fasting in pregnancy compared with that found in other parts of the world, especially in Middle East countries where about 70-90\% of pregnant women adhere to fasting ${ }^{(11,12)}$. The proportions of fasting mothers during pregnancy differed across ethnicities in the present study (78.9\% in Moroccan, $21.7 \%$ in Turkish and $40 \%$ in other ethnicities). Proportions were also different between trimesters of pregnancy and slightly higher in the first trimester. This finding is similar to a previous study ${ }^{(11)}$, and might be due to the fact that during the first trimester of pregnancy, women were still unaware about their pregnancy or because the burden of pregnancy is lower ${ }^{(12)}$. Our findings indicate that Ramadan fasting in the first trimester may lead to a decrease in birth weight of newborns, highlighting the need for further study.

In the present study, birth weight among newborns of women who fasted during the first trimester was $272 \mathrm{~g}$ lower than that among newborns of non-fasting women. Fasting in the second and third trimesters was not associated with birth weight. This corresponds with a previous finding that newborns whose mothers fasted in their first trimester had a 1.5 -fold risk for low birth weight than those of non-fasting mothers ${ }^{(9)}$. In contrast, this finding is different from a study in Saudi Arabia, which showed similar birth weights in newborns who were exposed to Ramadan in the first, second, or third trimester of pregnancy compared with those who were unexposed ${ }^{(31)}$. However, in that study, actual adherence to fasting was not recorded, and confounders may be an issue since effect estimates were only adjusted for sex, study duration and gestational age.

Possibly, placental and fetal growth trajectories are both irreversibly affected by maternal endocrine and metabolic alterations caused by Ramadan fasting. A study has shown that Ramadan exposure in the second and third trimesters, but not in the first trimester, of pregnancy is associated with a smaller placenta ${ }^{(31)}$. The placenta responds to the limited ability of the mother to deliver nutrients to it by slowing its growth but increasing its efficiency, so that fetal growth is sustained. Since similar changes were not found in the placenta of newborns who were exposed to Ramadan in the first trimester of pregnancy, it was speculated that this placental adaptation appears later in the pregnancy, when maternal blood supply is estab- lished. The fact that in the present study, birth weights were lowest among newborns of women who fasted in early pregnancy may indicate a maladaptive placental response towards dietary changes during Ramadan. Fasting early in pregnancy, during critical period of organogenesis, may also imply metabolic alterations in other organ systems, as has been demonstrated in animal models of undernutrition ${ }^{(32)}$.

Our findings suggest that Ramadan fasting during early pregnancy may reduce the birth weight of newborns. It is still unknown to what extent this reduction relates to perinatal morbidity and mortality. Further studies with a larger sample size are needed to provide more robust evidence.

\section{Acknowledgements}

The authors' contributions are as follows: R. J. G. v. E., R. C. P. and T. J. R. contributed to the study concept and design; N. Y. and J. B. acquired the data; A. I. S., C. S. P. M. U. and T. J. R. analysed, interpreted the data and drafted the manuscript; R. J. G. v. E., D. E. G., R. C. P., C. S. P. M. U. and T. J. R. critically reviewed the manuscript for important intellectual content; A. I. S. performed the statistical analysis. All authors read and approved the final manuscript.

None of the authors has any conflicts of interest to declare.

\section{References}

1. Wu G, Imhoff-Kunsch B \& Girard AW (2012) Biological mechanisms for nutritional regulation of maternal health and fetal development. Paediatr Perinat Epidemiol 26, $4-26$.

2. Mparmpakas D, Goumenou A, Zachariades E, et al. (2013) Immune system function, stress, exercise and nutrition profile can affect pregnancy outcome: lessons from a Mediterranean cohort. Exp Ther Med 5, 411-418.

3. Tegethoff M, Greene N, Olsen J, et al. (2010) Maternal psychosocial adversity during pregnancy is associated with length of gestation and offspring size at birth: evidence from a population-based cohort study. Psychosom Med $\mathbf{7 2}$, 419-426.

4. Stein AD, Zybert PA, Margot B, et al. (2004) Intrauterine famine exposure and body proportions at birth: The Dutch Hunger Winter. Int J Epidemiol 33, 831-836.

5. Roseboom TJ, Painter RC, van Abeelen AF, et al. (2011) Hungry in the womb: what are the consequences? Lessons from the Dutch famine. Maturitas 70, 141-145.

6. Barker DJP (2007) The origins of the developmental origins theory. J Intern Med 261, 412-417.

7. Roseboom T, de Rooij S \& Painter R (2006) The Dutch famine and its long-term consequences for adult health. Early Hum Dev 82, 485-491.

8. Van Ewijk R (2011) Long-term health effects on the next generation of Ramadan fasting during pregnancy. $J$ Health Econ 30, 1246-1260.

9. Ziaee V, Kihanidoost Z, Younesian M, et al. (2010) The effect of Ramadan fasting on outcome of pregnancy. Iran J Pediatr 20, 181-186.

10. Kavehmanesh Z \& Abolghasemi H (2004) Maternal Ramadan fasting and neonatal health. J Perinatol 24, 748-750.

11. Arab M \& Nasrollahi S (2001) Interrelation of Ramadan fasting and birth weight. Med J Islam Acad Sci 14, 91-95. 
12. Almond D \& Mazumder B (2011) Health capital and the prenatal environment: the effect of Ramadan observance during pregnancy. Am Econ J Appl Econ 3, 56-85.

13. van Ewijk RJG, Painter RC \& Roseboom TJ (2013) Associations of prenatal exposure to Ramadan with small stature and thinness in adulthood: results from a large Indonesian population-based study. Am J Epidemiol 177, 729-736.

14. Makki A (2002) Impact of Ramadan fasting on birth weight in 4 hospitals in Sana'a city, Yemen. Saudi Med $J \mathbf{2 3}$, $1419-1420$

15. Alwasel SH, Abotalib Z, Aljarallah JS, et al. (2011) Sex differences in birth size and intergenerational effects of intrauterine exposure to Ramadan in Saudi Arabia. Am J Hum Biol 23, 651-654.

16. Al-Hourani H \& Atoum M (2007) Body composition, nutrient intake and physical activity patterns in young women during Ramadan. Singapore Med J 48, 906-910.

17. Dikensoy E, Balat O, Cebesoy B, et al. (2008) Effect of fasting during Ramadan on fetal development and maternal health. J Obstet Gynaecol Res 34, 494-498.

18. Ozturk E, Balat O, Ugur MG, et al. (2011) Effect of Ramadan fasting on maternal oxidative stress during the second trimester: a preliminary study. J Obstet Gynaecol Res 37, 729-733.

19. Cross JH, Eminson J \& Wharton BA (1990) Ramadan and birth weight at full term in Asian Moslem pregnant women in Birmingham. Arch Dis Child 65, 1053-1056.

20. Alwasel SH, Abotalib Z, Aljarallah JS, et al. (2011) Secular increase in placental weight in Saudi Arabia. Placenta 32, 391-394.

21. Almond D \& Mazumder B (2008) Health capital and the prenatal environment: the effect of maternal fasting during pregnancy. Cambridge. http://www.nber.org/papers/w14428.
22. Awwad J, Usta I, Succar J, et al. (2012) The effect of maternal fasting during Ramadan on preterm delivery: a prospective cohort study. BJOG 119, 1379-1386.

23. Shahgheibi S, Ghadery E \& Pauladi A (2005) Effects of fasting during the third trimester of pregnancy on neonatal growth indices. Ann Alquds Med 1, 58-62.

24. Mirghani HM, Weerasinghe DSL, Ezimokhai M, et al. (2003) The effect of maternal fasting on the fetal biophysical profile. Int J Gynecol Obstet 81, 17-21.

25. Dikensoy E, Balat O, Cebesoy B, et al. (2009) The effect of Ramadan fasting on maternal serum lipids, cortisol levels and fetal development. Arch Gynecol Obstet 279, 119-123.

26. Moradi M (2011) The effect of Ramadan fasting on fetal growth and Doppler indices of pregnancy. J Res Med Sci 16, 165-169.

27. Prentice AM, Prentice A, Lamb WH, et al. (1983) Metabolic consequences of fasting during Ramadan in pregnant and lactating women. Hum Nutr Clin Nutr 37, 283-294.

28. Malhotra A, Scott PH, Scott J, et al. (1989) Metabolic changes in Asian Muslim pregnant mothers observing the Ramadan fast in Britain. Br J Nutr 61, 663-672.

29. Hizli D, Yilmaz SS, Onaran Y, et al. (2012) Impact of maternal fasting during Ramadan on fetal Doppler parameters, maternal lipid levels and neonatal outcomes. J Matern Fetal Neonatal Med 25, 975-977.

30. Rabinerson D, Dicker D, Kaplan B, et al. (2000) Hyperemesis gravidarum during Ramadan. J Psychosom Obstet Gynecol 21, 189-191.

31. Alwasel SH, Abotalib Z, Aljarallah JS, et al. (2010) Changes in placental size during Ramadan. Placenta 31, 607-610.

32. Harding J, Jaquiery A, Hernandez C, et al. (2011) Animal studies of the effects of early nutrition on long-term health. Nestle Nutr Workshop Ser Paediatr Program 68, 1-11. 